\title{
Phenoxydifluoromethyl Substituted Nitrogen Heterocycles. Synthesis and Heterocyclization Reactions of Ethyl 4,4-Difluoro- 4-phenoxyacetoacetate
}

\section{S.Yu. Solodukhin, A.S. Peregudov, E.V. Vorontsov and N.D. Chkanikov*}

A. N. Nesmeyanov Institute of Organoelement Compounds (INEOS), Russian Academy of Sciences, Vavilov Str. 28, 119991 Moscow, Russia

* Author to whom correspondence should be addressed. Phone: (+7) 095 135-6489. E-mail: nchkan@ineos.ac.ru

Received: 15 January 2004 / Accepted: 18 January 2004 / Published: 28 February 2004

\begin{abstract}
Ethyl 4,4-difluoro-4-phenoxyacetoacetate was obtained and studied as a precursor to new heterocyclic compounds. 6-Hydroxypyrimidine, 1,3-dihydro-1,5benzodiazepin-2-one, quinolin-2-one and 6-hydroxypyrazolo[3,4-b]pyridine derivatives containing phenoxydifluoromethyl groups were synthesized. These results make it possible to introduce aryloxydifluoromethyl substituents for the design of biologically active heterocycles.
\end{abstract}

Keywords: Ethyl 4,4-difluoro-4-phenoxyacetoacetate, heterocyclization reactions, phenoxydifluoromethyl group, biologically active heterocycles.

\section{Introduction}

For the most part, a search for biologically active compounds in the series of polyfluoroalkylated heterocycles follows the path of synthesis of various heterocyclic structures containing a limited set of polyfluoroalkyl substituents [1,2]. Development of methodology for introduction of new, functionally modified groups into the heterocyclic skeleton extends the range of the design of the bioactive derivatives. In this work, the introduction of aryloxydifluoromethyl groups into nitrogen heterocycles was studied. The only known case of such a modification is a reaction of 2-(bromodifluoro- 
methyl)benzoxazole with phenols in the presence of sodium hydride to give 2-(aryloxydifluoromethyl)benzoxazoles. Some of these compounds have been reported to exhibit anti-HIV activity. However, a wider use of this method is hindered due to the presence of nucleophilic groups and mobile protons in the heterocycle as well as the inaccessibility of such starting materials as $\mathrm{CF}_{2} \mathrm{Br}$-substituted heterocycles. Besides, the reactivity of the $\mathrm{CF}_{2} \mathrm{Br}$ group depends substantially on the chemical environment in the heterocycle [3]. Thus, the above method, as any other one, which involves a chemical transformation of polyfunctional compounds, could be applied only for specific cases. To create a chemical basis for a wider use of aryloxydifluoromethyl groups the general precursors to the corresponding heterocycles are needed. We have chosen ethyl 4,4-difluoro-4-phenoxyacetoacetate (1) as a target precursor.

\section{Results and Discussion}

To synthesize ketoester 1 we used a way similar to the described method for preparing ethyl esters of acetoacetic and 4,4,4-trifluoroacetoacetic acids, i.e. the Claisen condensation in the presence of various bases such as alkali metal alkoxides and hydrides [4,5]. The known methyl phenoxydifluoroacetate [6] was used as a starting material. Its reaction with ethyl acetate in the presence of sodium hydride leads to the target ketoester 1 in $75 \%$ yield (Scheme 1)

\section{Scheme 1}

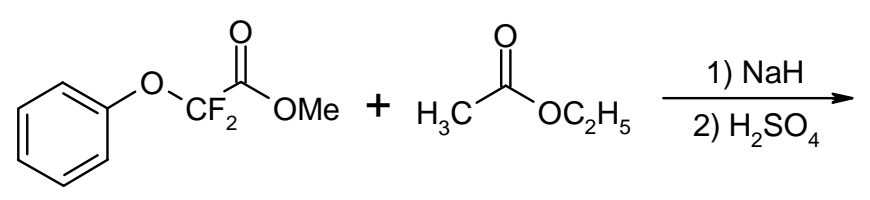<smiles>CCOC(=O)CC(=O)[Te+]Oc1ccccc1</smiles>

The reactivity of $\mathbf{1}$ in heterocyclization reactions with nitrogen-containing nucleophiles was found to be similar to that of well studied ethyl 4,4,4-trifluoroacetoacetate [7,8]. For example, the reaction of 1 with benzamidine at room temperature leads to 2-phenyl-4-(phenoxydifluoromethyl)-6-hydroxypyrimidine (2) in 93\% yield (Scheme 2).

\section{Scheme 2}

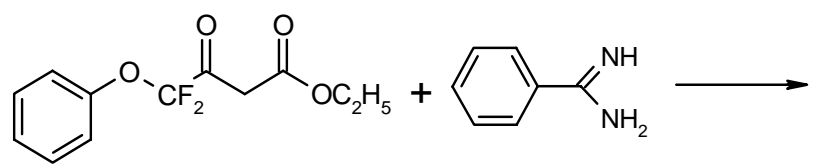

1<smiles>Oc1cc(C(F)(F)F)nc(-c2ccccc2)n1</smiles>

2 
Reaction of ethyl 4,4,4-trifluoroacetoacetate with o-phenylenediamine is known to give two different products depending on the conditions [8]. In basic and neutral media 4-trifluoromethyl-1,3dihydro-1,5-benzodiazepin-2-one is formed in high yield, whereas in an acidic medium 3-(2benzimidazolyl)-1,1,1-trifluoromethyl-2-propanone is only formed in low yield. In a similar way, the reaction of 1 with o-phenylenediamine in benzene under neutral conditions, furnished 4-(phenoxydifluoromethyl)-1,3-dihydro-1,5-benzodiazepin-2-one (3) in good yield (Scheme 3).

\section{Scheme 3}

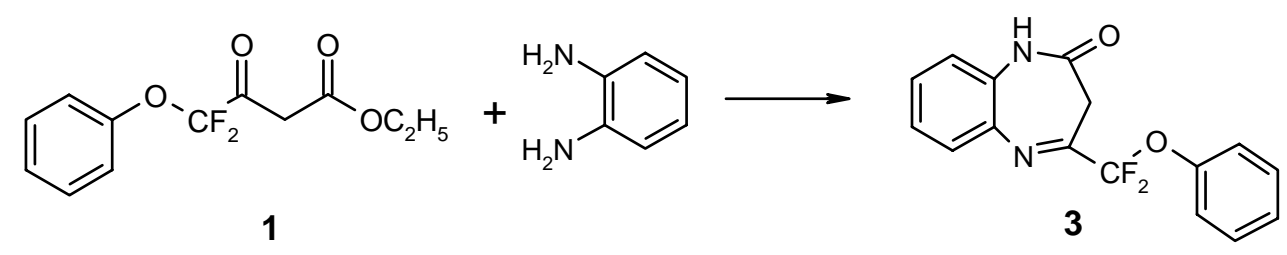

Upon heating 1 with $p$-anizidine in polyphosphoric acid, 2-(phenoxydifluoromethyl)-6-methoxy$1 \mathrm{H}$-quinoline-4-one (4) was obtained in $47 \%$ yield (Scheme 4 ).

\section{Scheme 4}

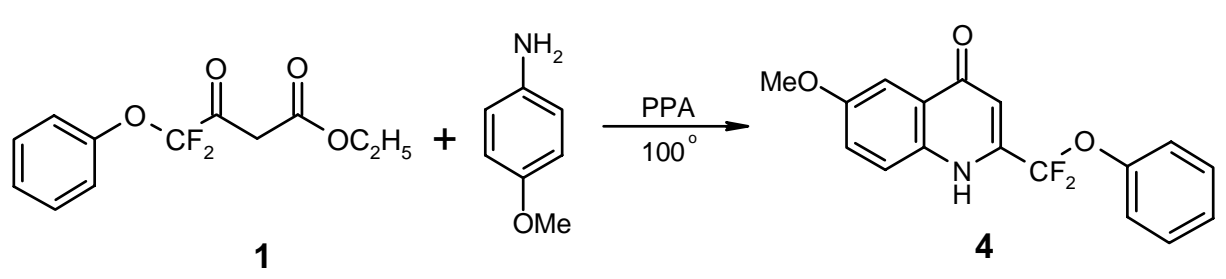

Reactions of ethyl 4,4,4-trifluoroacetoacetate with aminopyrazoles to give pyrazolo[3,4$b$ ]pyridines were thoroughly studied by Balicki et al. [9]. In particular, it was shown that the use of glacial acetic acid as a medium prevents the addition of the ester to the amino group due to protonation of the latter and promotes the attack at C-4 position of the pyrazole ring. For example, 6-hydroxy-2methyl-4-trifluoromethylpyrazolo[3,4-b]pyridine was selectively prepared in a high yield by reaction of ethyl 4,4,4-trifluoroacetoacetate with 1-methyl-3-aminopyrazole [9]. 5-Aminopyrazoles also have two reactive sites, the amino group and $\mathrm{C}-4$ position of the pyrazole ring. In this work, the reaction of 5-amino-1-(3-chlorophenyl)-3-methylpyrazole with ester $\mathbf{1}$ was carried out in glacial acetic acid under reflux conditions and gave 1-(3-chlorophenyl)-4-(phenoxydifluoromethyl)-6-hydroxypyrazolo-[3,4b]pyridine (5) in high yield (Scheme 5). 


\section{Scheme 5}

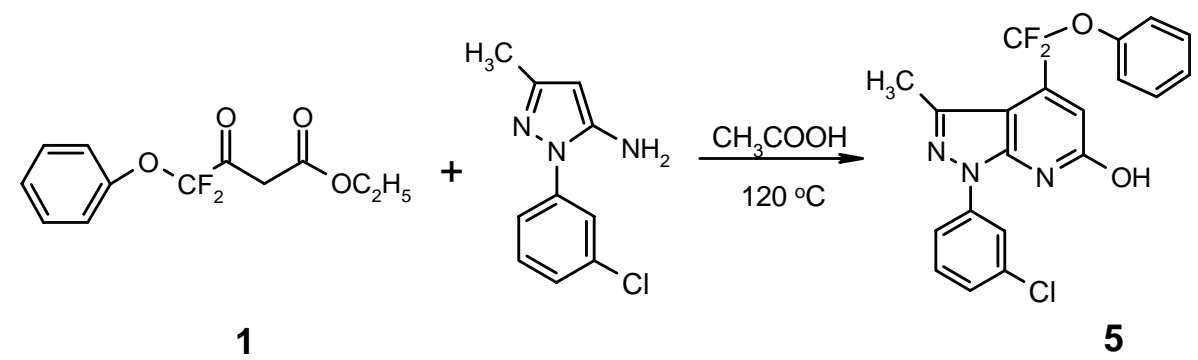

\section{Conclusions}

Ethyl (phenoxydifluoromethyl)acetoacetate is a valuable precursor to various heterocycles substituted with a phenoxydifluoromethyl group.

\section{Experimental}

\section{General}

${ }^{1} \mathrm{H}-,{ }^{13} \mathrm{C}$ - and ${ }^{19} \mathrm{~F}-\mathrm{NMR}$ spectra were obtained on a Bruker AMX-400 instrument operating at 400.1, 100.6 and $376.5 \mathrm{MHz}$, respectively. Chemical shifts in the ${ }^{1} \mathrm{H}-$ and ${ }^{13} \mathrm{C}-\mathrm{NMR}$ spectra were calculated from residual signals of deuterated solvents $\left(2.51 \mathrm{ppm}\right.$ for DMSO- $\mathrm{d}_{6}$ and $7.27 \mathrm{ppm}$ for $\mathrm{CDCl}_{3}$ ). Chemical shifts in ${ }^{19} \mathrm{~F}-\mathrm{NMR}$ spectra were obtained using trifluouroacetic acid as an external standard. In the case of 5, the assignments of signals in ${ }^{1} \mathrm{H}$ - and ${ }^{13} \mathrm{C}$ - spectra were performed on a Bruker Avance-300 spectrometer $\left(300.1 \mathrm{MHz}\right.$ for ${ }^{1} \mathrm{H}$ and $75.5 \mathrm{MHz}$ for ${ }^{13} \mathrm{C}$ ) using ${ }^{1} \mathrm{H}-\mathrm{NOESY}$, ${ }^{1} \mathrm{H}-\mathrm{COSY},{ }^{1} \mathrm{H}^{13} \mathrm{C}-\mathrm{HSQC}$ and HMBC experiments. The mass spectra were obtained on a Kratos MS 890 spectrometer at $70 \mathrm{eV}$ using a direct inlet system and with an ion source temperature of $250^{\circ}$. Methyl phenoxydifluoroacetate was synthesized according to the method of Yagupol'skii and Korin'ko [6]. Commercially unavailable 5-amino-1-(3-chlorophenyl)-3-methylpyrazole was synthesized according to the standard synthetic procedure by the reaction of 3-chlorophenylhydrazine hydrochloride with 3-aminocrotononitrile.

Ethyl 4,4-difluoro-4-phenoxyacetoacetate (1). To a solution of methyl phenoxydifluoroacetate $(9 \mathrm{~g}$, $4.5 \mathrm{mmol})$ in dry ethyl acetate $(8.8 \mathrm{~g}, 10 \mathrm{mmol})$ sodium hydride $(60 \%$ suspension in mineral oil, $1.8 \mathrm{~g})$ was added while cooling with ice water. The mixture was stirred until the solid phase dissolved (about $15 \mathrm{~min})$. Dry ether $(50 \mathrm{~mL})$ was added to the resultant solution and the mixture was heated under reflux for $8 \mathrm{hr}$. Ether and ethyl acetate were removed under reduced pressure and the residue was dissolved in ether and treated with diluted sulfuric acid (20\%). The organic layer was separated and the aqueous layer was extracted with ether $(2 \times 50 \mathrm{~mL})$. The combined organic phase was dried over sodium sulfate for $2 \mathrm{hr}$. Ether was removed under a reduced pressure and the residue was distilled to give $8.72 \mathrm{~g}(75 \%)$ of 1 as a colorless liquid: b.p. $85-88^{\circ} / 0.5 \mathrm{mmHg} ; n_{24}^{d}=1,4718 ;{ }^{1} \mathrm{H}-\mathrm{NMR}\left(\mathrm{CDCl}_{3}\right) \delta$ 
1.29-1.35 (m, 3H, $\mathrm{CH}_{2} \mathbf{C H}_{3}$ ), 3.81-3.87 (m, 2H, $\mathrm{CH}_{2}{ }^{\text {keto }}$ ), 4.25-4.31 (m, $2 \mathrm{H}, \mathbf{C H}_{2} \mathrm{CH}_{3}$ ), 5.72 (s, $\mathrm{CH}^{\mathrm{enol}}$ ), 7.21-7.41 (m, 5H, $\mathrm{H}_{\mathrm{Ar}}$ ), 12.00 (broad s, $\mathrm{OH}^{\mathrm{enol}}$ ).

6-Hydroxy-4-(phenoxydifluoromethyl)-2-phenylpyrimidine (2). To a solution of benzamidine (0.12 g, $0.1 \mathrm{mmol})$ in $10 \mathrm{~mL}$ of dry acetonitrile was added $0.3 \mathrm{~g}(0.12 \mathrm{mmol})$ of 1 . The mixture was stirred at room temperature for $2 \mathrm{hr}$. The precipitate of $2(0.06 \mathrm{~g})$ was filtered off, washed with petroleum ether and dried. The mother liquor was concentrated to $4 \mathrm{~mL}$ and kept at room temperature for 5 days. The precipitate was filtered off, washed with petroleum ether several times and dried to obtain a total of $0.29 \mathrm{~g}(93.5 \%)$ of 2 as colorless crystalline compound: ${ }^{1} \mathrm{H}-\mathrm{NMR}$ (DMSO- $\left.\mathrm{d}_{6}\right) \delta 6.77(\mathrm{~s}, 1 \mathrm{H}$, $\mathrm{CH}_{\text {pyrimidine) }}$ ), 7.20-7.96 (m, 10H, $\mathrm{H}_{\mathrm{Ar}}$ ), 11.13 (s, $1 \mathrm{H}$, exchangeable with $\mathrm{D}_{2} \mathrm{O}, \mathrm{OH}$ ); ${ }^{19} \mathrm{~F}-\mathrm{NMR}$ (DMSO$\left.\mathrm{d}_{6}\right) \delta 9.63$ (s, $\mathrm{CF}_{2} \mathrm{OAr}$ ); MS m/z 314, $\mathrm{M}^{+}$; Analysis: Calculated for $\mathrm{C}_{17} \mathrm{H}_{12} \mathrm{~F}_{2} \mathrm{~N}_{2} \mathrm{O}_{2}: \mathrm{C}$ 64.97; H 3.85; N 8.91. Found: C $64.81 ; \mathrm{H} 3.97$; N 8.94 .

4-(Phenoxydifluoromethyl)-1,3-dihydro-1,5-benzodiazepin-2-one (3). To a solution of o-phenylenediamine $(0.11 \mathrm{~g}, 0.1 \mathrm{mmol})$ in dry benzene $(15 \mathrm{~mL})$ was added $0.3 \mathrm{~g}(0.12 \mathrm{mmol})$ of $\mathbf{1}$. The mixture was heated under reflux for $1.5 \mathrm{hr}$ with a Dean-Stark device. The mixture was then cooled and kept at $5^{\circ}$ for $0.5 \mathrm{hr}$. The precipitate was filtered off, washed with petroleum ether and dried to obtain $0.3 \mathrm{~g}$

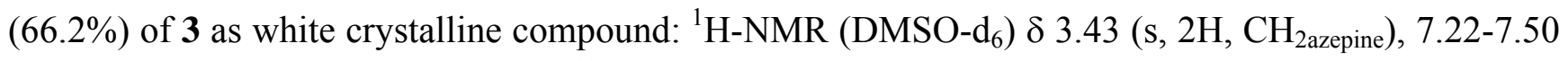
(m, 9H, $\mathrm{H}_{\mathrm{Ar}}$ ), $10.72(\mathrm{~s}, 1 \mathrm{H}, \mathrm{NH}) ;{ }^{19} \mathrm{~F}-\mathrm{NMR}\left(\mathrm{DMSO}_{-} \mathrm{d}_{6}\right) \delta 3.54\left(\mathrm{~s}, \mathrm{CF}_{2} \mathrm{OAr}\right) ; \mathrm{MS} \mathrm{m} / \mathrm{z} 302, \mathrm{M}^{+}$; Analysis: Calculated for $\mathrm{C}_{16} \mathrm{H}_{12} \mathrm{~F}_{2} \mathrm{~N}_{2} \mathrm{O}_{2}$ : C 63.58; H 4.00; N 9.27. Found: C 63.58; H 4.05; N 9.31

2-(Phenoxydifluoromethyl)-6-methoxy-1H-quinoline-4-one (4). p-Anisidine (0.11 g, $0.14 \mathrm{mmol})$ was suspended in polyphosphoric acid $(15 \mathrm{~mL})$. The suspension was heated to $60^{\circ}$ and treated with $0.4 \mathrm{~g}$ $(0.16 \mathrm{mmol})$ of 1 . The reaction mixture was then heated at $100^{\circ}$ for $3 \mathrm{hr}$. After cooling the mixture was treated with $200 \mathrm{~mL}$ of ice water. The solid formed was filtered off, washed several times with water and a small amount of ether and dried to obtain $0.18 \mathrm{~g}(46 \%)$ of 4 as pale brown solid: ${ }^{1} \mathrm{H}-\mathrm{NMR}$ $\left(\right.$ DMSO-d $\left._{6}\right) \delta 3.88\left(\mathrm{~s}, 3 \mathrm{H}, \mathrm{OCH}_{3}\right), 6.98$ (broad. s., $1 \mathrm{H}$, exchangeable with $\left.\mathrm{D}_{2} \mathrm{O}, \mathrm{NH}\right), 7.35-7.97(\mathrm{~m}, 9 \mathrm{H}$,

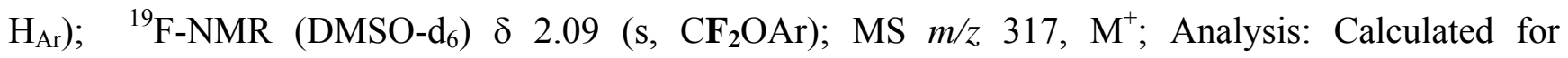
$\mathrm{C}_{17} \mathrm{H}_{13} \mathrm{~F}_{2} \mathrm{NO}_{2}$ : C 67.77; H 4.35; N 4.65. Found: C 67.69; H 4.21; N 4.48.

1-(3-Chlorophenyl)-3-methyl-4-(phenoxydifluoromethyl)-6-hydroxypyrazolo[3,4-b]pyridine (5). To a solution of 5-amino-1-(3-chlorophenyl)-3-methylpyrazole $(0.2 \mathrm{~g}, 0.1 \mathrm{mmol})$ in glacial acetic acid (6 $\mathrm{mL})$ was added $0.3 \mathrm{~g}(0.12 \mathrm{mmol})$ of $\mathbf{1}$. The mixture was heated under reflux for $6 \mathrm{hr}$. The solution was then cooled to room temperature, poured into $20 \mathrm{~mL}$ of ice water and kept at $2^{\circ}$ for 2 days. The precipitate formed was filtered off, washed with petroleum ether and dried to obtain $0.36 \mathrm{~g}(90 \%)$ of 5 as white solid: ${ }^{1} \mathrm{H}-\mathrm{NMR}\left(\mathrm{DMSO}_{6} \mathrm{~d}_{6}\right) \delta 2.61\left(\mathrm{~s}, 3 \mathrm{H}, \mathrm{CH}_{3}\right), 6.99(\mathrm{~s}, 1 \mathrm{H}, \mathrm{CH} 5), 7.30-7.40\left(\mathrm{~m}, 4 \mathrm{H}, \mathrm{H}_{\mathrm{Ar}}\right.$ ), 7.40-7.50 (m, 2H, $\mathrm{H}_{\mathrm{Ar}}$ ), 7.56 (t, 1H, J = 8.5 Hz, H5'), 8.18 (broad d, 1H, J = 8.5Hz, H6'), 8.31 (broad $\mathrm{t}, 1 \mathrm{H}, \mathrm{J}=2.0 \mathrm{~Hz}, \mathrm{H} 2$ '), $12.23(\mathrm{~s}, 1 \mathrm{H}, \mathrm{OH}) ;{ }^{19} \mathrm{~F}-\mathrm{NMR}\left(\mathrm{DMSO}_{6}\right) \delta 14.07\left(\mathrm{~s}, \mathbf{C F}_{2} \mathrm{OPh}\right) \cdot{ }^{13} \mathrm{C}-\left\{{ }^{1} \mathrm{H}\right\}$ NMR* (DMSO-d 6 ) $\delta 15.3\left(\mathrm{~s}, \mathrm{CH}_{3}\right), 104.6$ (s, C5), 106.3 (s, C3a), 119.4 (s, C2'), 120.4 (s, C6'), 120.6 (t, J = 261.6 Hz, CF $), 121.9$ (s, C3", C5"), 125.9 (s, C4'), 126.9 (s, C4"), 130.5 (s, C2”, C6”), 131.2 
(s, C3'), 133.9 (s, C5'), 137.5 (t, J = 34.6 Hz, C4), 140.4 (s, C1'), 142.4 (s, C3), 149.8 (s, C1'), 151.2 (s, C7a), 164.2 (s, C6); MS m/z 401, $\mathrm{M}^{+}$; Analysis: Calculated for $\mathrm{C}_{20} \mathrm{H}_{14} \mathrm{~F}_{2} \mathrm{~N}_{3} \mathrm{O}_{2}$ : C 59.79; $\mathrm{H}$ 3.51; N 10.46. Found: C 59.76; H 3.41; N 10.52 .

* Atoms in $\mathbf{5}$ are numbered as follows:

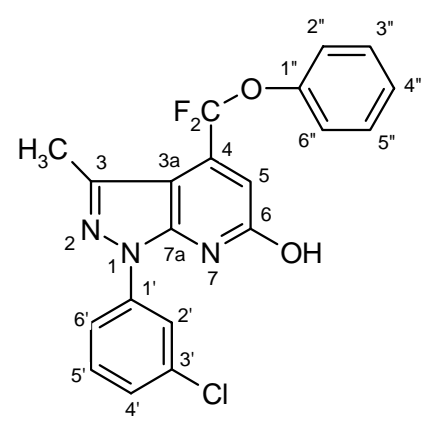

\section{References}

1. Furin, G. G. Zh. Org. Chim. 1994, 30, 1704; CAN 101:191768.

2. Erian, A. W. J. Heterocycl. Chem. 2001, 38, 793.

3. Burkholder, C. R.; Dolbier, W. R.; Medetielle, Jr,. M. J. Fluorine Chem. 2001, 109, 39.

4. Henne, A.; Newman, M.; Quill, L.; Stainforth, R. J. Am. Chem. Soc. 1947, 69, 1819.

5. McBee, E.; Pierce, O.; Kilbourn, H.; Wilson E. J. Am. Chem. Soc. 1953, 75, 1749.

6. Yagupol'skii, L. M.; Korin'ko, V. A. Zh. Obshch. Khim. 1969, 39, 1749 [CAN 71:123853].

7. Bergmann, E. D.; Cohen, S.; Shahak, I. J. Chem. Soc. 1959, 11, 3278.

8. Wigton, F. B.; Joullie, M. M. J. Am. Chem. Soc. 1959, 81, 5212.

9. Balicki, R. Pol. J. Chem. 1983, 57, 413.

Sample availability: Contact authors.

(C) 2004 by MDPI (http:www.mdpi.org). Reproduction is permitted for noncommercial purposes. 